\title{
Corrosion Mitigation by an Eco-Friendly Inhibitor: Nerium Oleander Leaf Extract on Carbon Steel in an Acidic Medium
}

\author{
J. Arockia Selvi ${ }^{a,}{ }^{*}$, M. Arthanareeswari ${ }^{a}$, P. Kamaraj ${ }^{b}$, T. Pushpa Malini ${ }^{a}$, \\ V. Elumalai ${ }^{c}$, S. Revathi ${ }^{a}$ and N. Subasree ${ }^{a}$ \\ ${ }^{a}$ Department of Chemistry, SRM Institute of Science and Technology, \\ Kattankulathur - 603203, India \\ ${ }^{b}$ Department of Chemistry, Vel Tech Rangarajan Dr.Sanguthala R\&D Institute of Science and \\ Technology, Avad i- 600002, India \\ ${ }^{c}$ Department of Chemistry, Chevron Science Center, University of Pittsburgh, \\ Pittsburgh, P.O. Box 15260, United States
}

Received June 14, 2018; accepted August 05, 2020

\begin{abstract}
The inhibitory activity of ethanol extract of Nerium oleander leaf (NOLE) on carbon steel corrosion in $0.5 \mathrm{M}$ and $1.0 \mathrm{M}$ of hydrochloric acid solutions was studied by weight loss method and electrochemical techniques. The inhibition efficiency $\left(\eta_{\mathrm{w}}\right)$ increased with an increase in the concentration of NOLE and in temperature. Polarisation curves indicated that NOLE acts as a mixed type of inhibitor. The changes in charge transfer resistance $\left(\mathrm{R}_{\mathrm{t}}\right)$ with increasing inhibitor (i.e. NOLE) concentration assured the adsorption of the inhibitor onto the metal surface. The results of $\eta_{w}, \eta_{p}$ (inhibition efficiency obtained from polarisation study) and $\eta_{R}$ (inhibition efficiency obtained from impedance analysis) are in par with each other. Surface morphology study uncovered the coating of the inhibitor molecule on the metal surface. The phenomenon of physical adsorption has been established based on the inhibition efficiency of the inhibitor with change in temperature.
\end{abstract}

Keywords: carbon steel, corrosion inhibition, Nerium oleander leaf extract, electrochemical techniques.

\section{Introduction}

Pickling is defined as a chemical or electrochemical process in which surface oxides are removed from the metal [1]. It is a common method for cleaning steel products. Aggressive acid solutions are extensively used for acid pickling. The most commonly used acids in industrial process are hydrochloric acid, sulphuric acid and nitric acid. Hydrochloric acid is used in pickling baths, because of its

\footnotetext{
* Corresponding author. E-mail address: arockiaselvi.jo@ktr.srmuniv.ac.in
} 
regeneration from the depleted pickling solution. The use of acid makes the metal structures to corrode causing economic losses. Hence, pickling is carried out using acid with some additives, called corrosion inhibitors. Most of the corrosion inhibitors in an acidic medium are organic compounds containing hetero atoms such as nitrogen, sulphur and oxygen. However, they are not eco-friendly and are very expensive. Due to such limitations, there is a drive for searching suitable eco-friendly corrosion inhibitors, extracted from plant parts that contain different organic compounds such as alkaloids, tannins and amino acids. Natural products extracted from leaves, seeds or barks of plants have been utilized as corrosion inhibitors for carbon steel along with the pickling bath solution. Salghi et al. showed the decrease in the corrosion rate of $\mathrm{C} 38$ steel in an acidic medium, in the presence of green tea extract [2]. Thao and Dung studied the relative stable nature of $3.00 \mathrm{~g} \mathrm{~L}^{-1}$ of caffeine as corrosion inhibitor, for about 10 days, in an acidic medium [3]. The effectiveness of pickling in acids increased with an increase in temperature. However, the objects must not be pickled at higher temperatures. The inhibitors adsorbed onto the metal surface should be stable at the operating temperature of the pickling bath. The effect of temperature on the corrosion inhibition efficiency of natural products was also investigated. Verma and Khan studied the effect of temperature and inhibitor concentrations on mild steel corrosion using Bryophyllumpinnatum leaf extract. They found that the inhibition efficiency increased as the inhibitor concentration increased, but decreased as the temperature increased, thus obeying Langmuir adsorption isotherm [4]. Desai studied the influence of Ankado (Calotropisgigantea) leaves on mild steel corrosion in an acidic medium, which were found to obey Temkin's adsorption isotherm [5]. Kairi and Kassim studied the inhibition efficiency of Curcuma longa extract at different temperatures, and found that it was physically adsorbed onto the metal surface with an endothermic reaction [6]. Alaneme et al. showed that the functional groups $\mathrm{O}-\mathrm{H}, \mathrm{C}-\mathrm{N}$ and unsaturated $\mathrm{C}=\mathrm{C}$, present in Hunteria umbellata adsorbed onto the metal surface, obeyed Langmuir adsorption isotherm [7]. Inhibition was essentially high by adsorption through the functional groups present in the extract, while the activation energies and Langmuir adsorption isotherms confirmed the mechanism to be physical adsorption [8]. Fouda et al. found that the spontaneous physical and chemical adsorption of Thevetiaperuviana extract obeyed Temkin adsorption isotherm on $\mathrm{C}$-steel in $1 \mathrm{M}$ of ydrochloric acid [9]. Thus, the present work investigates the inhibition efficiency of Nerium oleander leaf extract on carbon steel corrosion by weight loss method and electrochemical techniques. Thermodynamic adsorption parameters were used to clarify the adsorption behaviour of an inhibitor at different temperatures $(303-288 \mathrm{~K})$ in 0.5 and $1 \mathrm{M}$ of hydrochloric acid solutions.

\section{Materials and methods}

\section{Preparation of metal specimen}

Chemical composition of the carbon steel specimen was measured using Optical Emission Spectrometer (Foundry-Master, WAS, Germany) by ChemicalOES test, according to the ASTM E415-15 method (C: $0.419 \%, \mathrm{Mn}: 0.760 \%$, Si: 
$0.239 \%$, P: $0.014 \%$, Ni: $0.028 \%$, Cr: $1.079 \%$, Mo: $0.274 \%, \mathrm{Cu}:<0.001 \%, \mathrm{Nb}$ : $<0.002 \%, \mathrm{~W}:<0.010 \%$ and $\mathrm{V}: 0.050 \%)$. The metal specimen with the dimensions $1.0 \times 4.0 \times 0.2 \mathrm{~cm}^{3}$ was polished to a mirror finish, degreased with acetone and used for the weight loss method.

\section{Preparation of Nerium oleander leaf extract}

$100 \mathrm{~g}$ of shade air-dried Nerium oleander leaves were soaked with $1000 \mathrm{~mL}$ of reagent grade ethanol for $24 \mathrm{~h}$. The ethanolic solution was filtered and heated at $60{ }^{\circ} \mathrm{C}$ for removal of ethanol. The stock solution of the Nerium oleander leaf extract was prepared by dissolving $1 \mathrm{~g}$ of dried extract in dimethyl sulphoxide and diluting it to $100 \mathrm{~mL}$ with distilled water. It was filtered again to remove suspended particles, and the filtrate was used for further studies.

\section{Weight loss method}

The volume of the experimental solution (corrosive medium) was $100 \mathrm{~mL}$. The hydrochloric acid was used as an experimental solution. The metal coupons were put into the experimental solution with the help of hooks. The experiment was carried out in the absence and presence of different extracts concentrations. The initial weights of the metal coupons were noted and then these were completely immersed into the experimental solution at $30^{\circ} \mathrm{C}$, for about $1 \mathrm{~h}$. After the period of immersion, the metal coupons were taken out, washed thoroughly with distilled water, dried and weighed. The final weight was noted. From the initial and final weights of the metal coupons, the loss in weight was calculated and tabulated. The corrosion rate can be calculated using the following equation [10]:

$$
v=\frac{K \times W}{\rho A t}
$$

where $\mathrm{W}$ is the weight loss (mg) after exposure time, $\mathrm{A}$ is the area of the exposed specimen $\left(\mathrm{in}^{2}\right), \rho$ is the density of specimen $\left(\mathrm{g} \mathrm{cm}^{-3}\right)$ and $\mathrm{t}$ is the time of exposure (h). $\mathrm{K}$ is a constant and its magnitude depends on the system of used units. The inhibition efficiency from weight loss was calculated as follows:

$$
\eta_{W} \%=\frac{v_{0}-v}{v_{0}} \times 100
$$

where $v_{0}$ and $v$ represents the corrosion rate of the metal without and with the inhibitor, respectively.

\section{Electrochemical techniques}

Potentiodynamic polarisation study was carried out using (Bio-Logic Science Instruments, Seyssinet-Pariset, France) a three-electrode cell assembly. The working electrode was a rectangular specimen of carbon steel with one face of the electrode constant with $1 \mathrm{~cm}^{2}$ of exposed area. A saturated calomel electrode (SCE) was used as reference electrode. A time interval of $30 \mathrm{~min}$ was given for 
the system to attain a steady-state open circuit potential. The potentiodynamic current-potential curves were recorded by changing the electrode potential from -0.025 to $0.025 \mathrm{~V}$ vs OCP with a scan rate of $1 \mathrm{mV} \mathrm{s}^{-1}$. Potential (E) vs $\log$ current (I) plots were then recorded. The results, such as corrosion current $\left(\mathrm{I}_{\text {corr }}\right)$ and corrosion potential ( $\mathrm{E}_{\text {corr }}$ ), were determined from $\mathrm{E}$ vs $\log$ I plots. Tangents were drawn on the cathodic and anodic polarisation curves. The inhibition efficiency $\left(\eta_{\mathrm{p}}\right)$ was calculated using the following equation:

$$
\eta_{\mathrm{p}} \%=\frac{I_{\text {corr }}-I_{\text {corr(inhi) }}}{I_{\text {corr }}} \times 100
$$

where $I_{\text {corr }}$ and $I_{\text {corr(inhi) }}$ represent corrosion current density values without and with the inhibitor, respectively. Electrochemical impedance spectroscopy (EIS) study was carried out in the frequency range from $10 \mathrm{kHz}$ to $0.01 \mathrm{~Hz}$, with 10 $\mathrm{mV}$ AC amplitude. The values of charge transfer resistance $\left(\mathrm{R}_{\mathrm{t}}\right)$ and double-layer capacitance $\left(C_{d l}=1 / 2 \pi f_{\max } R_{t}\right)$ were extracted from non-linear least square fit results of impedance data $\left(Z^{*}(\omega)\right)$. The inhibition efficiency was estimated using the following relation:

$$
\eta_{\mathrm{R}} \%=\frac{R_{\mathrm{t}(\mathrm{inhi})}-R_{\mathrm{t}}}{R_{\mathrm{t}(\mathrm{inhi})}} \times 100
$$

where $R_{t}$ and $R_{t(\text { inhi) }}$ are the charge transfer resistance for carbon steel in the absence and presence of the inhibitors, respectively.

\section{Field emission scanning electron microscopic studies}

The carbon steel specimens were immersed in blank, as well as inhibitor solutions, for a period of $1 \mathrm{~h}$, after which the specimens were taken and dried. The nature of the film formed on the surface of the metal specimens was analysed by various surface analysis techniques. The surface morphology measurements of carbon steel were examined using the FEI Quanta FEG 200 high-resolution scanning electron microscope (SEM) model. It provided the information about the sample surface topography.

\section{Results and discussion Weight loss measurements}

The weight loss $(\mathrm{W})$, corrosion rate $(v)$ and inhibition efficiency $\left(\eta_{\mathrm{w}}\right)$ were calculated from the results of weight loss study for different concentrations of inhibitor (NOLE) in steps of 50 to $250 \mathrm{ppm}$, in both $0.5 \mathrm{M}$ and $1.0 \mathrm{M}$ of hydrochloric acid solutions, and are shown in Table 1 . The comparison of $\mathrm{W}, v$ and $\eta_{\mathrm{w}}$ of carbon steel exposed to 0.5 and $1.0 \mathrm{M}$ of hydrochloric acid solution, as a function of NOLE concentration, is shown in Fig. 1(a)-(c), respectively. Fig. 1(a) displays the reduction in weight loss (W) of metal coupons with an increasing concentration of NOLE in both cases of 0.5 and $1.0 \mathrm{M}$ of an hydrochloric acid medium, respectively. The same trend observed in the case of 
corrosion rate $(v)$ is as shown in Fig. 1(b). The data from Table 1 clearly show that the values of $\mathrm{W}$ and $v$ for $1.0 \mathrm{M}$ of hydrochloric acid were fivefold higher than those for a $0.5 \mathrm{M}$ of the acidic hydrochloric medium. As it can be seen from the figure, the decreasing trend of both parameters ( $\mathrm{W}$ and $v$ ) has shown uniformity in either of the acidic solutions. However, the decrease in the $\mathrm{W}$ and $v$ parameters dominates at higher concentrations (greater than $100 \mathrm{ppm}$ ), and this is due to the fact that an increasing concentration of NOLE induced an adsorption of the inhibitor onto the metal-solution interface. Besides, the decrease was found to be bi-exponential in both cases. This may be due to the two different ways of adsorption: one relating to the uniform adsorption at the aforesaid interface, where the concentration ranged to the maximum of $100 \mathrm{ppm}$ of NOLE; and the other relating to the slow adsorption at a saturated level of the concentrations above $100 \mathrm{ppm}$ of NOLE. On the other hand, Fig. 1(c) exhibits an exponential growth of $\eta_{w}$ as a function of NOLE concentration. As observed from $\mathrm{W}$ and $v, \eta_{\mathrm{w}}$ also displays a bi-exponential nature. Hence, the results demonstrate high inhibition efficiency of $83.1 \%$ and $69.9 \%$ for the concentration of $250 \mathrm{ppm}$ of NOLE in 0.5 and $1.0 \mathrm{M}$ of hydrochloric acid, respectively.
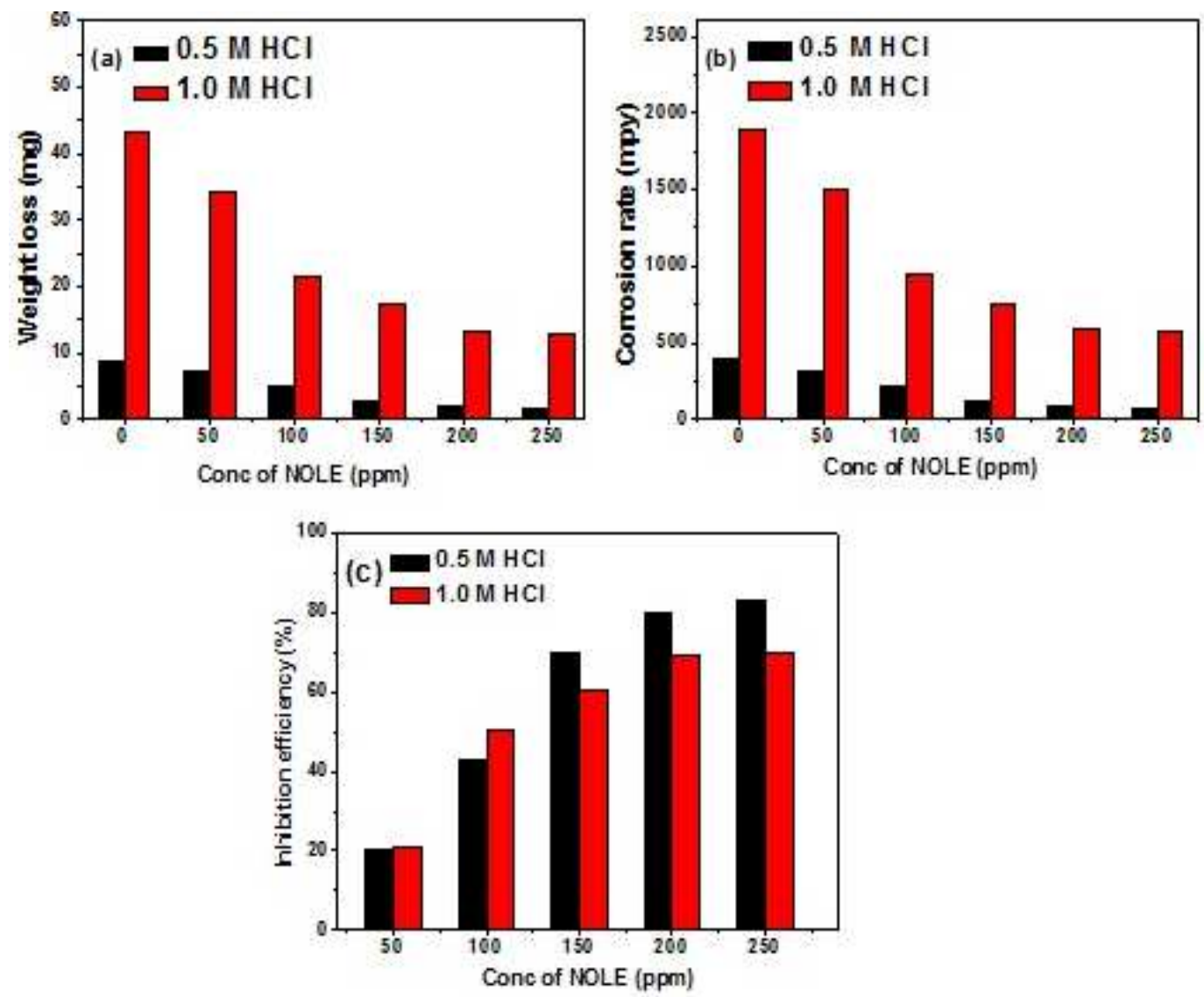

Figure 1. Comparison of a) weight loss ( $\mathrm{mg}$ ), b) corrosion rate (mpy) and c) inhibition efficiency $(\%)$ studied for carbon steel in 0.5 and $1.0 \mathrm{M}$ of hydrochloric acid solutions, respectively.

The corrosion rate decreases from 390.1 to $65.75 \mathrm{mpy}$ in $0.5 \mathrm{M}$ of hydrochloric acid, and from 1893.5 to $569.5 \mathrm{mpy}$ in $1.0 \mathrm{M}$ of the hydrochloric acid solution with $250 \mathrm{ppm}$ of NOLE. The studies were extended to other acidic 
media [11]; however, from the present study, the obtained results indicate that NOLE could act as an excellent corrosion inhibitor in an hydrochloric acid solution. The studies were carried out at different temperatures ranging from 303 to $328 \mathrm{~K}$, in order to study the temperature effect on NOLE inhibition efficiency.

Table 1. Corrosion rates (mpy) for carbon steel immersed in hydrochloric acid without and with inhibitors, and the inhibition efficiencies $\left(\eta_{\mathrm{w}}\right)$ obtained by weight loss method.

\begin{tabular}{|c|c|c|c|c|}
\hline $\begin{array}{c}\text { Acidic } \\
\text { medium }\end{array}$ & $\begin{array}{c}\text { Concentration of } \\
\text { NOLE }(\mathbf{p p m})\end{array}$ & $\begin{array}{c}\text { Weight loss, } \boldsymbol{W} \\
(\mathbf{m g})\end{array}$ & $\begin{array}{c}\text { Corrosion rate, } \boldsymbol{v} \\
(\mathbf{m p y})\end{array}$ & $\boldsymbol{\eta}_{\mathbf{w}}(\boldsymbol{\%})$ \\
\hline \multirow{4}{*}{$0.5 \mathrm{M}$} & 0 & 8.9 & 390 & - \\
\cline { 2 - 5 } & 50 & 7.1 & 311 & 20.2 \\
\cline { 2 - 5 } & 100 & 5.1 & 224 & 42.6 \\
\cline { 2 - 5 } & 150 & 2.7 & 118 & 69.6 \\
\cline { 2 - 5 } & 200 & 1.8 & 79 & 79.7 \\
\hline \multirow{4}{*}{$1.0 \mathrm{M}$} & 250 & 1.5 & 66 & 83.1 \\
\cline { 2 - 5 } & 0 & 43.2 & 1894 & - \\
\cline { 2 - 5 } & 50 & 34.3 & 1503 & 20.6 \\
\cline { 2 - 5 } & 100 & 21.5 & 942 & 50.2 \\
\cline { 2 - 5 } & 150 & 17.2 & 754 & 60.1 \\
\hline
\end{tabular}

\section{Effect of temperature on corrosion inhibition}

The effect of temperature on the corrosion inhibition efficiency of NOLE for carbon steel in 0.5 and $1.0 \mathrm{M}$ of hydrochloric acid solutions was studied by weight loss measurements, in the absence and presence of $250 \mathrm{ppm}$ of NOLE at three different temperatures: 308, 318 and $328 \mathrm{~K}$. The results are shown in Table 2. The inhibition efficiency increased with a rise in the temperature from 308 to $328 \mathrm{~K}$.

Table 2. Corrosion rates for carbon steel immersed in various acidic solutions in the absence and presence of inhibitors at various temperatures (303, 308, 318 and $328 \mathrm{~K}$ ) for about $1 \mathrm{~h}$.

\begin{tabular}{|c|c|c|c|c|c|c|c|c|c|}
\hline \multirow{2}{*}{$\begin{array}{c}\text { Acidic } \\
\text { medium }\end{array}$} & $\begin{array}{c}\text { Concentration } \\
\text { of }\end{array}$ & \multicolumn{9}{|c|}{ Temperature (K) } \\
\cline { 3 - 11 } & $\begin{array}{c}\text { NOLE } \\
(\mathbf{p p m})\end{array}$ & $\begin{array}{c}\mathbf{3 0 3} \\
(\mathbf{m p y})\end{array}$ & $\begin{array}{c}\boldsymbol{\eta}_{\mathbf{w}} \\
(\boldsymbol{\%})\end{array}$ & $\begin{array}{c}\mathbf{C R} \\
(\mathbf{m p y})\end{array}$ & $\begin{array}{c}\boldsymbol{\eta}_{\mathbf{w}} \\
(\boldsymbol{\%})\end{array}$ & $\begin{array}{c}\text { CR } \\
(\mathbf{m p y})\end{array}$ & $\begin{array}{c}\boldsymbol{\eta}_{\mathbf{w}} \\
(\boldsymbol{\%})\end{array}$ & $\begin{array}{c}\text { CR } \\
(\mathbf{m p y})\end{array}$ & $\begin{array}{c}\boldsymbol{\eta}_{\mathbf{w}} \\
(\boldsymbol{\%})\end{array}$ \\
\hline $0.5 \mathrm{M}$ & 0 & 390 & - & 28,285 & - & 25,988 & - & 24,515 & - \\
& 250 & 66 & 83.1 & 21,399 & 13.56 & 21,228 & 18.32 & 9174 & 72.62 \\
\hline \multirow{2}{*}{$1.0 \mathrm{M}$} & 0 & 1894 & - & 33,119 & - & 40,855 & - & 46,562 & - \\
\cline { 2 - 11 } & 250 & 570 & 69.9 & 15,955 & 51.83 & 17,568 & 57.0 & 10,471 & 77.1 \\
\hline
\end{tabular}

The inhibitor showed maximum IE of $13.56 \%$ at $308 \mathrm{~K}$, which increased to $72.62 \%$ at $328 \mathrm{~K}$ in $0.5 \mathrm{M}$ of hydrochloric acid. Similarly, in $1.0 \mathrm{M}$ of hydrochloric acid, $51.83 \%$ of IE increased to $77.1 \%$. Fig. 2 shows the decrease in 
the corrosion rate values in $1.0 \mathrm{M}$ of hydrochloric acid were higher or lower than those in $0.5 \mathrm{M}$ of hydrochloric acid in the absence (blank) and presence of 250 ppm of NOLE. Fig. 3 shows the Langmuir adsorption isotherm by plotting log $(\theta / 1-\theta)$ against $\log \mathrm{C}$ for both 0.5 and $1.0 \mathrm{M}$ of hydrochloric acid solutions. The plot gave a linear relationship with $\mathrm{R}^{2}$ values (0.9818 and 0.9450$)$, indicating the strong adherence to Langmuir adsorption isotherm [12]. The standard Gibbs free energy $\left(\Delta \mathrm{G}_{\mathrm{ads}}^{\circ}\right)$ and equilibrium constant $\left(\mathrm{K}_{\mathrm{ads}}\right)$ are calculated at different temperatures for $250 \mathrm{ppm}$ of NOLE using the following relations [13].

$$
\begin{aligned}
\Delta G_{\mathrm{ads}}^{\circ} & =-2.303 R T \log \left(55.5 K_{\mathrm{ads}}\right) \\
K_{\mathrm{ads}} & =\frac{\theta}{C(1-\theta)}
\end{aligned}
$$

where $\theta=\eta / 100$, the degree of surface coverage of the metal surface and $C$ is the inhibitor concentration, $\mathrm{R}$ is the universal gas constant, $\mathrm{T}$ is the absolute temperature and 55.5 is the concentration of water in the solution ( $\left.\mathrm{mol} \mathrm{L}^{-1}\right)$. The values of $\mathrm{K}_{\mathrm{ads}}$ and $\Delta \mathrm{G}_{\text {ads }}^{\circ}$ obtained from the above equation are listed in Table 3.
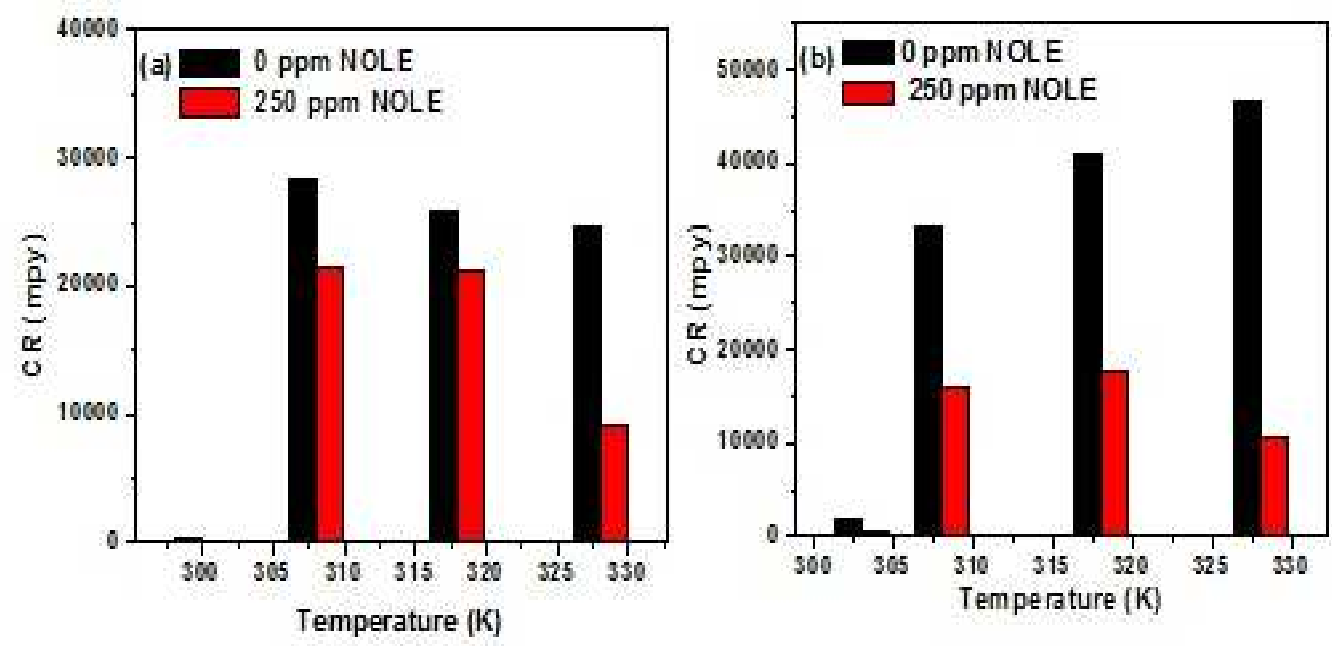

Figure 2. Effect of temperature on the corrosion rates of carbon steel in (a) $0.5 \mathrm{M}$ of hydrochloric acid and (b) $1.0 \mathrm{M}$ hydrochloric of acidic solutions, respectively, for blank and $250 \mathrm{ppm}$ of NOLE.

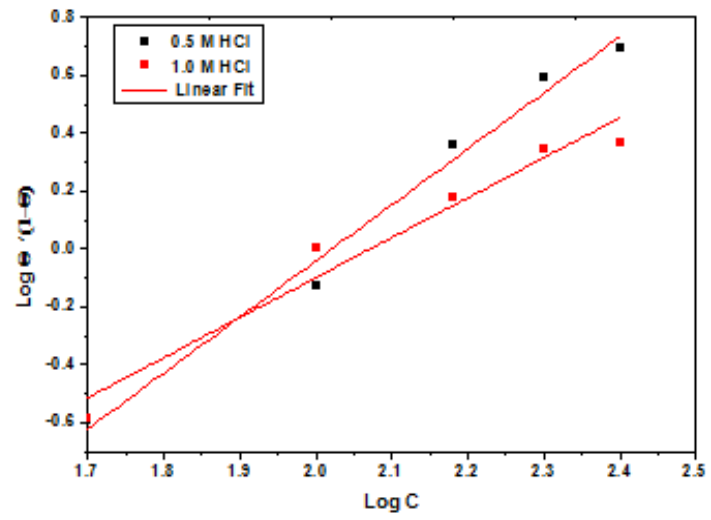

Figure 3. Langmuir isotherm for the adsorption of the inhibitor onto the surface of carbon steel in 0.5 and $1.0 \mathrm{M}$ of hydrochloric acid solutions by using surface coverage values calculated by weight loss method at $303 \mathrm{~K}$. 
It is noted that $\Delta \mathrm{G}_{\text {ads }}^{\circ}$ values decreased with an increase in temperature, indicating a strong and spontaneous adsorption of the inhibitor molecule onto the metal surface [14]. The negative value of standard free energy reveals the spontaneity of the adsorption of the inhibitor onto the metal surface [15]. Also, the increase in the equilibrium constant $\left(\mathrm{K}_{\mathrm{ads}}\right)$ shows the maximum surface coverage $(\theta)$, with an increase in concentration as well as in temperature [16]. Generally, $\Delta \mathrm{G}_{\text {ads }}^{\circ}$ values of $-20 \mathrm{~kJ} \mathrm{~mol}^{-1}$ or lower (less negative value) show the mode of adsorption as an electrostatic interaction between the charged inhibitor molecule and the charged metal surface (physisorption). Those with more negative values than - $40 \mathrm{~kJ} \mathrm{~mol}^{-1}$ involve charge sharing or transfer from the inhibitor molecules to the metal surface to form a coordinate type of bond (chemisorption). Hence, the adsorption of NOLE onto the metal surface is regarded as physical adsorption, since the calculated values of $\Delta \mathrm{G}_{\text {ads }}^{\circ}$ vary from 15.96 to $-23.43 \mathrm{~kJ} \mathrm{~mol}^{-1}$ and -16.01 to $-21.54 \mathrm{~kJ} \mathrm{~mol}^{-1}$, in $0.5 \mathrm{M}$ and $1.0 \mathrm{M}$ of hydrochloric acid solutions, respectively. $\Delta \mathrm{G}_{\text {ads }}^{\circ}$ value decreased (more negative value) with a rise in temperature in both the acidic media, indicating a strong binding between the inhibitor molecule and the metal surface. However, the adsorption was still physical adsorption rather than chemical adsorption, as $\Delta \mathrm{G}_{\text {ads }}^{\circ}$ values were still lower than $-40 \mathrm{~kJ} \mathrm{~mol}^{-1}$.

Table 3. Equilibrium constant and standard free energy values for carbon steel in 0.5 and $1.0 \mathrm{M}$ of hydrochloric acid solutions in the presence of different concentrations of NOLE at $303 \mathrm{~K}$ and at various temperatures for $250 \mathrm{ppm}$ of NOLE.

\begin{tabular}{|c|c|c|c|c|c|}
\hline $\begin{array}{c}\text { Concentration of } \\
\text { NOLE } \\
(\text { ppm) }\end{array}$ & $K_{\text {ads }}$ & $\begin{array}{c}-\Delta G_{\text {ads }}^{\circ} \\
\left(\mathbf{k J ~ m o l}^{-1}\right)\end{array}$ & $\begin{array}{c}\text { Concentration of } \\
\text { NOLE } \\
(\text { ppm) }\end{array}$ & $\boldsymbol{K}_{\text {ads }}$ & $\begin{array}{c}-\Delta \boldsymbol{G}_{\text {ads }}^{\circ}(\mathbf{k J} \\
\left.\mathbf{m o l}^{-1}\right)\end{array}$ \\
\hline \multicolumn{3}{|l|}{$0.5 \mathrm{M} \mathrm{HCl}$} & \multicolumn{3}{|l|}{$1.0 \mathrm{M} \mathrm{HCl}$} \\
\hline 50 & 10.1 & 15.96 & 50 & 10.4 & 16.01 \\
\hline 100 & 29.7 & 18.66 & 100 & 40.3 & 19.43 \\
\hline 150 & 91.6 & 21.50 & 150 & 60.3 & 20.45 \\
\hline 200 & 157.0 & 22.86 & 200 & 88.6 & 21.42 \\
\hline 250 & 196.7 & 23.43 & 250 & 92.9 & 21.54 \\
\hline $\begin{array}{c}\text { Temperature (K) } \\
(250 \mathrm{ppm} \text { of NOLE) }\end{array}$ & $K_{\text {ads }}$ & $\begin{array}{c}-\Delta G_{\text {ads }}^{\circ} \\
\left(\mathbf{k J ~ m o l}^{-1}\right)\end{array}$ & $\begin{array}{c}\text { Temperature } \\
\text { (K) } \\
\text { (250 ppm of NOLE) }\end{array}$ & $\boldsymbol{K}_{\text {ads }}$ & $\begin{array}{c}-\Delta G_{\text {ads }}^{\circ} \\
\left(\mathbf{k J ~ m o l}^{-1}\right)\end{array}$ \\
\hline \multicolumn{3}{|l|}{$0.5 \mathrm{M} \mathrm{HCl}$} & \multicolumn{3}{|l|}{$1.0 \mathrm{M} \mathrm{HCl}$} \\
\hline 308 & 6.3 & 14.99 & 308 & 43.0 & 19.92 \\
\hline 318 & 9.0 & 16.42 & 318 & 53.0 & 21.12 \\
\hline 328 & 106.1 & 23.68 & 328 & 134.7 & 24.33 \\
\hline
\end{tabular}

\section{Potentiodynamic polarisation curves}

Potentiondyanamic polarisation curves for carbon steel in $0.5 \mathrm{M}$ and $1.0 \mathrm{M}$ of hydrochloric acid solutions, in the absence and presence of inhibitor (NOLE) at 
$303 \mathrm{~K}$, are shown in Fig. 4. Addition of NOLE to the hydrochloric acid solutions decreased remarkably the corrosion rate by shifting the anodic and cathodic curves to lower current densities. The adsorption of the inhibitor onto the metal surface increased in the presence of $250 \mathrm{ppm}$ of NOLE, which was confirmed with the decrease in the corrosion current densities. The corrosion parameters, such as corrosion potential $\left(\mathrm{E}_{\mathrm{corr}}\right)$, corrosion current densities $\left(\mathrm{I}_{\mathrm{corr}}\right)$, anodic tafel slope $\left(b_{a}\right)$ and cathodic tafel slope $\left(b_{c}\right)$, obtained from potentiodynamic polarisation curves, are shown in Table 4.
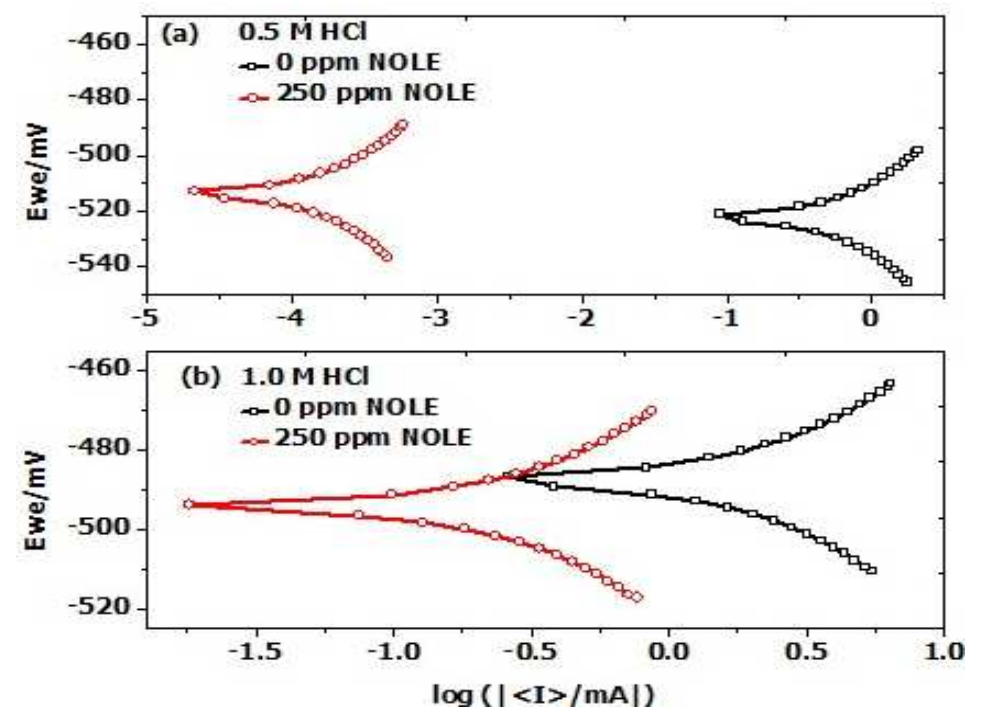

Figure 4. Potentiodynamic polarisation curves of carbon steel in $0.5 \mathrm{M}$ of hydrochloric acid (a) and 1.0 M of hydrochloric acid (b) without and with NOLE.

The positive shift in $E_{\text {corr }}$ value by the addition of the inhibitor shows predominantely the control of the anodic reaction. However, the displacement of the $\mathrm{E}_{\text {corr }}$ value is about $11 \mathrm{mV}$ from that of the blank solution. This reavels that the inhibitor acts as a mixed type of inhibitor $[17,18]$. The corrosion current densities $\left(\mathrm{I}_{\text {corr }}\right)$ drastically decreased from 486.61 to $133.44 \mu \mathrm{A} \mathrm{cm} \mathrm{cm}^{-2}$ with the addition of $250 \mathrm{ppm}$ of NOLE in $0.5 \mathrm{M}$ of hydrochloric acid, showing $\quad 74.65 \%$ $\eta_{\mathrm{p}}$. Similarly, in $1.0 \mathrm{M}$ of hydrochloric acid, the $\mathrm{I}_{\text {corr }}$ value decreased from 1041.34 to $491.16 \mu \mathrm{A} \mathrm{cm}^{-2}$ with $250 \mathrm{ppm}$ of NOLE, showing $52.83 \% \eta_{\mathrm{p}}$. The increase in corrosion inhibition efficiency in the presence of NOLE is attributed to the adsorption of the inhibitor molecule onto the metal surface[16].

Table 4. Electrochemical polarisation parameters obtained for carbon steel in 0.5 and $1 \mathrm{M}$ of hydrochloric acid solutions without and with NOLE.

\begin{tabular}{|c|c|c|c|c|c|c|c|}
\hline $\begin{array}{c}\text { Acidic } \\
\text { medium }\end{array}$ & $\begin{array}{c}\text { Concentration } \\
\text { of NOLE } \\
(\mathbf{p p m})\end{array}$ & $\begin{array}{c}\boldsymbol{E}_{\text {corr }} \\
(\mathbf{m V} \mathbf{~ v s} \\
\mathbf{S C E})\end{array}$ & $\begin{array}{c}\boldsymbol{I}_{\mathbf{c o r r}} \\
\left(\boldsymbol{\mu} \mathbf{~ c m}^{-2}\right)\end{array}$ & $\begin{array}{c}\boldsymbol{\beta}_{\mathbf{a}} \\
\left(\mathbf{m V} \mathbf{d e c}^{-\mathbf{1}}\right)\end{array}$ & $\begin{array}{c}\boldsymbol{\beta} \mathbf{c} \\
\left(\mathbf{m V ~ d e c}^{-\mathbf{1}}\right)\end{array}$ & $\begin{array}{c}\mathbf{C R} \\
(\mathbf{m p y})\end{array}$ & $\begin{array}{c}\boldsymbol{\eta} \mathbf{P} \\
(\boldsymbol{\%})\end{array}$ \\
\hline \multirow{2}{*}{$0.5 \mathrm{M}$} & 0 & -523 & 487.61 & 38 & 41 & 217 & - \\
\cline { 2 - 8 } & 250 & -515 & 133.44 & 39 & 40 & 59 & 72.58 \\
\hline \multirow{2}{*}{$1.0 \mathrm{M}$} & 0 & -510 & 1041.34 & 49 & 39 & 465 & - \\
\cline { 2 - 8 } & 250 & -505 & 491.16 & 39 & 40 & 219 & 52.83 \\
\hline
\end{tabular}




\section{Electrochemical impedance spectroscopy}

Fig. 5 illustrates the Nyquist plot from EIS studies for carbon steel in $0.5 \mathrm{M}$ and 1.0 $\mathrm{M}$ of an hydrochloric acid medium in the absence and presence of inhibitor (NOLE); the solid line corresponds to a least-squares fitting procedure adopted Z-fit using EC-lab software. Table 5 consolidates the fit results obtained from the fitting of impedance data in the absence and presence of NOLE at 250 ppm in 0.5 and $1.0 \mathrm{M}$ of an hydrochloric acid medium. In both acidic media, complex impedance data were found to be a depressed semicircle, rather than a perfect semicircle, indicating the frequency dispersion effect. Depressed semicircle is best represented by the constant phase element (CPE), which describes the heterogeneity in the system [19], of which impedance is given by the expression:

$$
K_{\mathrm{ads}}=\frac{\theta}{C(1-\theta)}
$$

where $\mathrm{Q}$ is the magnitude of $\operatorname{CPE}\left(\Omega^{-1} \mathrm{~s}^{\mathrm{n}} \mathrm{cm}^{-2}\right), \mathrm{j}$ is the imaginary number $\left(\mathrm{j}^{2}=\right.$ $-1)$, and $\mathrm{w}$ is the angular frequency $\left(\mathrm{rad}^{-1}\right)$. Moreover, $\mathrm{n}$ accounts for non-ideal behaviour, when it is $0 \leq n \geq 1$, resulting from non-uniform diffusion of the inhibitor molecules. This non-ideal behaviour may arise due to different physical phenomena such as surface inhomogeneity resulting from surface roughness, inhibitor adsorption and porous layer formation. The double-layer capacitance $\left(\mathrm{C}_{\mathrm{dl}}\right)$ can be simulated via $\mathrm{CPE}$ from the following relation [20]:

$$
C_{\mathrm{dl}}=Q_{\mathrm{dl}}\left(2 \pi f_{\max }\right)^{n-1}
$$
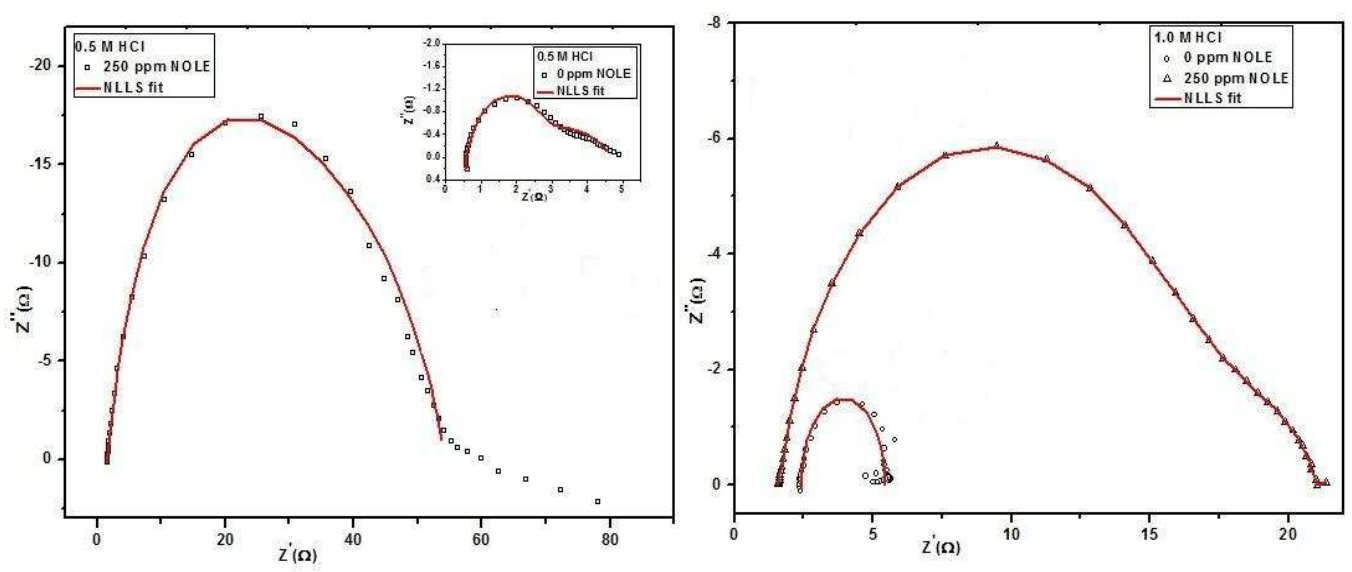

Figure 5. Nyquist plot for carbon steel in $0.5 \mathrm{M}$ and $1.0 \mathrm{M}$ of hydrochloric acid solutions without and with NOLE. The solid line shows the nonlinear least squares analysis (NLLS) fit routine.

The depressed semicircle constituent of the time constant corresponds to parallel combination of charge transfer resistance $\left(R_{t}\right)$ and double-layer capacitance $\left(C_{d l}\right)$. It indicates that the charge transfer processes during the polarisation upon the application of AC field were unaffected by the presence and absence of the inhibitor; however, the presence of the inhibitor increased the $\mathrm{R}_{\mathrm{t}}$ value to $51 \Omega$ 
$\mathrm{cm}^{2}$ (for $250 \mathrm{ppm}$ ) from $3.6 \Omega \mathrm{cm}^{2}$ (for $0 \mathrm{ppm}$ ) and exhibited the enhanced inhibition, due to passivation of the inhibitor at the metal surface for $0.5 \mathrm{M}$ of hydrochloric acid. The increasing $\mathrm{R}_{\mathrm{t}}$ indicates the increasing impedance and decreasing corrosion rate due to the inhibitor presence. This result was well supported by the corrosion rates studied through weight loss method. On the other hand, $\mathrm{C}_{\mathrm{dl}}$ was found to decrease from $394(0 \mathrm{ppm})$ to $78 \mu \mathrm{F} \mathrm{cm}{ }^{-2}(250 \mathrm{ppm})$ in $0.5 \mathrm{M}$ of hydrochloric acid. The decrease in $\mathrm{C}_{\mathrm{dl}}$ value shows the formation of a protective film on the metal surface. This indicates that the inhibitor adsorption at the metal/solution interface prohibits the charge transfer by increasing the $\mathrm{R}_{\mathrm{t}}$ values. Thus, $92.94 \%$ and $88.94 \%$ of inhibition efficiencies $\left(\eta_{R}\right)$ were observed for $250 \mathrm{ppm}$ of NOLE in $0.5 \mathrm{M}$ and $1.0 \mathrm{M}$ hydrochloric acid medium, respectively.

Table 5. Electrochemical impedance parameters obtained for carbon steel in 0.5 and $1.0 \mathrm{M}$ of hydrochloric acid solutions with different concentrations of NOLE as corrosion inhibitor.

\begin{tabular}{|c|c|c|c|c|c|c|c|c|}
\hline $\begin{array}{c}\text { Acidic } \\
\text { media }\end{array}$ & $\begin{array}{c}\text { NOLE } \\
\text { concentration } \\
(\mathbf{p p m})\end{array}$ & $\begin{array}{c}\boldsymbol{R}_{\mathbf{s}} \\
\left(\mathbf{\Omega} \mathbf{c m}^{2}\right)\end{array}$ & $\begin{array}{c}\boldsymbol{R}_{\mathbf{t}} \\
\left(\mathbf{\Omega} \mathbf{c m}^{2}\right)\end{array}$ & $\begin{array}{c}\boldsymbol{Q}_{\mathbf{d l}} \\
\left(\mathbf{m}^{-1} \mathbf{S}^{\mathbf{n}} \mathbf{c m}^{-2}\right)\end{array}$ & $\begin{array}{c}\boldsymbol{C}_{\mathbf{d l}} \\
\left(\boldsymbol{\mu} \mathbf{F} \mathbf{c m}^{-2}\right)\end{array}$ & $\boldsymbol{n}$ & $\begin{array}{c}\boldsymbol{f}_{\max } \\
(\mathbf{H z})\end{array}$ & $\begin{array}{c}\boldsymbol{\eta}_{\mathbf{R}} \\
(\boldsymbol{\%})\end{array}$ \\
\hline $0.5 \mathrm{M}$ & 0 & 0.6 & 3.6 & 1.785 & 394 & 0.819 & 672 & - \\
\cline { 2 - 9 } & 250 & 1.6 & 51 & 0.261 & 78 & 0.831 & 203 & 92.94 \\
\hline \multirow{2}{*}{$1.0 \mathrm{M}$} & 0 & 2.4 & 1.9 & 0.309 & 171 & 0.935 & 1441 & - \\
\cline { 2 - 9 } & 250 & 1.6 & 17.5 & 0.467 & 110 & 0.816 & 419 & 88.94 \\
\hline
\end{tabular}

\section{SEM analysis}

The surface morphology of the metal specimen immersed for $1 \mathrm{~h}$, in the absence and presence of $250 \mathrm{ppm}$ of NOLE, in $0.5 \mathrm{M}$ and $1.0 \mathrm{M}$ of hydrochloric acid solutions, was examined by scanning electron microscopy. The images are shown in Fig. 6.
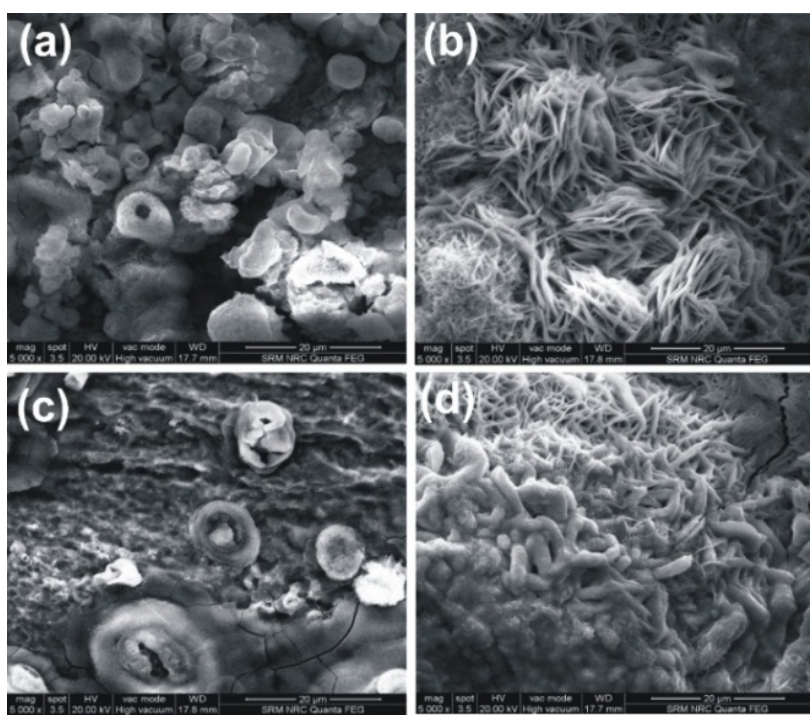

Figure 6. SEM images of carbon steel immersed in $0.5 \mathrm{M}$ of hydrochloric acid without (a) and with (b) inhibitor and in $1.0 \mathrm{M}$ of hydrochloric acid without (c) and with (d) inhibitor. 
The micrographs revealed the presence of pits on the metal surface which might be created due to the liberation of hydrogen gas in the acidic medium (Fig. $6 a)$. As the acid concentration was increased, the diameter of the pit became very large and the latter was full of black corrosion product (Fig. 6c). This is due to the continuous attack of $\mathrm{H}^{+}$ion and $\mathrm{Cl}^{-}$ion on the metal surface, which accelerated the corrosion rate with the increase in hydrochloric acid concentration [21]. Images shown in Fig. 6b and Fig. 6d reveal that the metal surface was densely covered by the inhibitor molecules. It is very interesting to note that the needle-structured inhibitor molecules adsorbed onto the active sites of the metal surface reduced the corrosion rate of carbon steel in the hydrochloric acid medium.

\section{Conclusions}

The ethanol extract of NOLE acts as a good corrosion inhibitor for carbon steel in $0.5 \mathrm{M}$ of hydrochloric acid. It has been found that the inhibition efficiency of the inhibitor increases with an increase in the concentration of NOLE and also with an increase in temperature. The maximum IE was $83.1 \% \eta_{w}$ for $250 \mathrm{ppm}$ of NOLE in $0.5 \mathrm{M}$ of the hydrochloric acid solution. Further, the experimental data obeyed Langmuir adsorption isotherm. The negative value of standard free energy reveals the spontaneity of adsorption of the inhibitor onto the metal surface. The increase in equilibrium constant $\left(\mathrm{K}_{\mathrm{ads}}\right)$ value showed the physisorption of the inhibitor molecule onto the metal surface. The inhibitor was adsorbed onto the metal/solution interface, decreasing the corrosion rate of carbon steel, acting as a mixed type of inhibitor and controlling both the anodic and cathodic reactions. The inhibitive action is thus controlled by concentration and temperature, and the data obtained are in good agreement with $\eta_{w}, \eta_{p}$ and $\eta_{R}$.

\section{Acknowledgement}

The authors would like to thank Nanotechnology Research Centre, SRM IST, Kattankulathur for providing us the FESEM facility.

\section{References}

1. Reidenbach F. ASM Handbook: Surface Engineering, Vol 5. United States of America (USA): ASM International; 1994.

2. Salghi R, Jodeh S, Ebenso EE, et al. Inhibition of C-steel corrosion by green tea extract in hydrochloric solution. Int J Electrochem Sci. 2017;12:32833295.

3. Thao TT, Dung DTK. Investigate the corrosion inhibitive ability of caffeine for CT3 steel in $1 \mathrm{M}$ hydrochloric acid solution by EIS technique. VNU J Sci Nat Sci Technol. 2016;32(2):65-70. 
4. Verma DK, Khan F. Corrosion inhibition of mild steel by extract of Bryophyllum pinnatum leaves in acidic solution. Chem Mater Res. 2015;7(5):69-76.

5. Desai PS. Inhibitory action of extract of ankado (Calotropis gigantea) leaves on mild steel corrosion in hydrochloric acidsolution. Int J Curr Microbiol Appl Sci. 2015;4(1):437-447.

6. Kairi NI, Kassim J. The effect of temperature on the corrosion inhibition of mild steel in $1 \mathrm{M}$ hydrochloric acid solution by Curcuma longa extract. Int $\mathbf{J}$ Electrochem Sci. 2013;8:7138-7155.

7. Alaneme KK, Olusegun SJ, Adelowo OT. Corrosion inhibition and adsorption mechanism, studies of Hunteria umbellata seed husk extracts. Alexandria Eng J. 2015;55:673-681.

8. Alaneme KK, Olusegun SJ, Alo AW. Corrosion inhibitory properties of elephant grass (Pennisetum purpureum) extract: Effect on mild steel corrosion in $1 \mathrm{M}$ hydrochloric acid solution. Alexandria Eng $\mathrm{J}$. 2016;55:1069-1076.

9. Fouda AS, Megahed HE, Fouad N, et al. Corrosion inhibition of carbon steel in $1 \mathrm{M}$ hydrochloric acid solution by aqueous extract of Thevetiaperuviana. $\mathrm{J}$ Biol Trib Corros. 2016;2(16):2-13

10. Callister WD Jr. Materials Science and Engineering: An Introduction. 7th ed. New York: Wiley; 2007.

11. Rajendran A. Isolation, characterization, pharmacological and corrosion inhibition studies of flavonoids obtained from Nerium oleander and Tecoma stans. Int J Pharm Tech Res. 2011;3(2):1005-1013.

12. Khadom AA. Effect of temperature on corrosion inhibition of copper-nickel alloy by tetraethylenepentamine under flow conditions. J Chil Chem Soc. 2014;59(3):2545-2549.

13. Obi-Egbedi NO, Essien KE, Obot IB, et al. 1,2-Diaminoanthraquinone as corrosion inhibitor for mild steel in hydrochloric acid: Weight loss and quantum chemical study. Int J Electrochem Sci. 2011;6:913-930.

14. Wei-Hua Li, Qiao He, Sheng-Tao Zhang et al. Some new triazole derivatives as inhibitors for mild steel corrosion in acidic medium. J Appl Electrochem. 2008;38:289-295.

15. Li X, Deng S, Fu H. Synergism between red tetrazolium and uracil on the corrosion of cold rolled steel in $\mathrm{H}_{2} \mathrm{SO}_{4}$ solution. Corros Sci. 2009;51:13441355.

16. Bentiss F, Lagrenée M, Traisnel M. 2,5-Bis(n-pyridyl)-1,3,4-oxadiazoles as corrosion inhibitors for mild steel in acidic media. Corrosion. 2000;56(7):733-742.

17. MigahedaMA, FaragaAA, Elsaeda SM, et al. Synthesis of a new family of Schiff base nonionic surfactants and evaluation of their corrosion inhibition effect on X-65 type tubing steel in deep oil wells formation water. Mater Chem Phys. 2011;125:125-135.

18. Al-SabaghAM, Nasser NM, Farag AA, et al. Structure effect of some amine derivatives on corrosion inhibition efficiency for carbon steel in acidic media 
using electrochemical and quantum theory methods. Egypt J Pet. 2013;22:101-116.

19. Amirudin A, Thierry D. Application of electrochemical impedance spectroscopy to study the degradation of polymer-coated metals. Prog Org Coat. 1995;26:1-28.

20. Boudalia M, Sebbar NK, Bourazmi H, et al. Anti-corrosive properties of benzothiazine derivatives on mild steel corrosion in $1 \mathrm{M}$ hydrochloric acid solution: Experimental and theoretical studies. J Mater Environ Sci. 2016;7(3):878-888.

21. Schweinsberg DP, Ashworth V. The inhibition of the corrosion of pure iron in $0.5 \mathrm{M}$ sulphuric acid by n-alkyl quaternary ammonium iodides. Corros Sci. 1988;28:539-545. 